\title{
DAS TÉCNICAS ESPECÍFICAS E DO MUNDO VIVIDO: IMPLICAÇÕES SOBRE O IMITAR E O CRIAR NA DANÇA
}

\author{
Danieli Alves Pereira Marques \\ Universidade Federal de Santa Catarina, Florianópolis, Santa Catarina, Brasil
}

Aguinaldo Cesar Surdi

Universidade Federal de Santa Catarina, Florianópolis, Santa Catarina, Brasil

Marília Del Ponte de Assis

Universidade Federal de Santa Catarina, Florianópolis, Santa Catarina, Brasil

\section{Elenor Kunz}

Universidade Federal de Santa Maria ,Santa Maria, Rio grande do Sul, Brasil

\begin{abstract}
Resumo
O presente estudo apresenta uma discussão referente à imitação e à criação de movimentos no contexto do ensino da dança. Trata-se de um ensaio teórico que fundamenta-se na fenomenologia de Merleau-Ponty $(1991,1999,1974)$, na teoria do "semovimentar" humano de Kunz (2001) e na concepção de mímesis de Wulf (2005). O estudo aponta a necessidade de se construírem estratégias pedagógicas para que haja espaço para uma "imitação criativa", uma aprendizagem que permita a busca de um estilo próprio na execução/experimentação dos movimentos. Alem disso, indica possibilidades de se estabelecer um diálogo que valorize as experiências trazidas do mundo vivido de cada sujeito - seu "mundo de movimentos" - e as diversas formas de dançar.
\end{abstract}

Palavras chave: Dança. Educação. Imitação. Criação.

\section{Introdução}

O presente estudo apresenta uma discussão referente à imitação e à criação de movimentos no contexto do ensino da dança com fins educati$\operatorname{vos}^{1}$. Trata-se de um ensaio teórico que busca fundamentação na fenomeno- 
logia de Merleau-Ponty $(1991,1999,1974)$, na teoria do "se-movimentar" humano de Kunz (2001) e na concepção de mímesis de Wulf (2005).

A dança a que nos referimos diz respeito àquela que é desenvolvida tanto no ensino curricular formal quanto no ensino extracurricular (projetos sociais, projetos extraclasses), mas com isso não queremos afirmar que essas reflexões não sirvam para diferentes espaços, instituições especializadas, academias, entre outros. Pelo contrário, o ideal seria que tais reflexões dialogassem com todos os contextos em que a dança se insere com intenção formadora.

Como já diagnosticado, a educação não se restringe somente ao contexto escolar, porém, concordamos com Gonzáles e Fensterseifer (2009, p. 21) que em sua condição republicana, "a escola é um lugar em que é possível defender e construir formas de olhar e sentir o mundo diferente daquelas que permitem outras instituições sociais" ${ }^{2}$.

Preocupa-nos o processo de ensino das técnicas específicas da dança que, durante as experiências, podem não deixar espaço para um "aprenderartístico", mas sim, centrar-se apenas em um "aprender-mecânico", pautado em ações reprodutivistas. Mas, qual seria a diferença existente entre um "aprender-artístico" e um "aprender-mecânico"? Supostamente esses são processos que se entrelaçam na discussão sobre imitação, criação, mundovivido e técnicas institucionalizadas.

Sendo assim, procuramos abordar qual a possibilidade de o "mundo de movimentos", ou seja, as experiências advindas do mundo-vivido dos sujeitos dialogarem com a aprendizagem das diversas técnicas específicas da dança durante o processo de ensino. Recorrendo à fenomenologia observamos que, durante seu desenvolvimento enquanto movimento filosófico, sempre se anunciou um "retorno" às experiências vividas, experiências essas que são reveladas na medida em que o "ser" se relaciona e se faz presente junto ao mundo. Merleau-Ponty (1999) na obra "Fenomenologia da Percep-

são disciplinas curriculares obrigatórias nos diversos níveis da Educação Básica. A dança também permanece estruturada nos Parâmetros Curriculares Nacionais do Ensino da Educação Física e da Arte (PCN's, 1997).

2 Entendemos ser importante mencionarmos como pensamos a escola, quando falamos nessa especificidade da "educação escolar", entretanto não havendo espaço suficiente para aprofundarmos essa discussão, destacamos a concepção de escola republicana dos autores González e Fensterseifer (2009), os quais, ao aprofundarem a discussão, apontam que, entre outros objetivos, a escola tem a função "de introduzir os alunos no mundo sociocultural que a humanidade tem construído, com o objetivo de que eles possam incluir-se no projeto, sempre renovado, da reconstrução desse mundo" (GONZÁLEZ e FENSTERSEIFER, 2009, p. 21).

Pensar a Prática, Goiânia, v. 17, n. 3, p. 849-864, jul./set. 2014 
ção" ressalta que retornar às coisas próprias é retornar a este mundo anterior ao conhecimento do qual o conhecimento sempre fala.

$\mathrm{O}$ mundo vivido pode ser compreendido como as experiências humanas que se configuram fundamentais no processo criativo nas artes. Como podemos observar, as expressões artísticas, especialmente as modernas, trazem o mundo percebido e criado pelo artista na sua vivência (MATTHEWS, 2010), e no universo artístico da dança isso não se torna diferente.

Como será apresentado, não se trata de afirmar que durante todo o segmento de ensino não se pode passar pelo processo de "imitação", aquele que inclui formas de dançar de determinada cultura de movimento, trazida pelo professor ou pelos próprios alunos, extraída de suas experiências cotidianas, pois isso, como será salientado, constitui condição importante para enriquecer o repertório de movimento dos sujeitos envolvidos.

O que colocamos em pauta, no entanto, é a importância de refletir sobre estratégias pedagógicas de como passar por essas etapas da aprendizagem sem impor uma forma "ideal e/ou fechada" de movimento aos sujeitos, sem esquecer que eles diferem entre si na maneira de aprender, de perceber, de sentir, de expressar. Portanto, apontaremos três etapas que consideramos importantes para o ensino da dança: a experimentação/investigação de movimentos, a aprendizagem das técnicas da dança e a oportunidade para a reelaboração da movimentação aprendida.

\section{Da imitação}

Ao nos questionarmos se existe a possibilidade, dentro do processo pedagógico, de um diálogo entre a imitação e a criação de movimentos na dança, partimos do pressuposto de que é preciso rever os conceitos de imitação existentes, assim como também refletir de que forma acontecem esses procedimentos durante as aulas. Procuraremos demonstrar que ambos os processos podem estar correlacionados e podem dialogar, desde que revisitado o conceito de imitação, e que esse possa ser estendido a situações práticas.

Antes de tudo, é preciso dizer que as ações miméticas se dão a partir de um ser corporal. Nesse sentido, recorremos a Merleau-Ponty (1999) para apontar a necessidade de crermos no corpo como espaço da existência, nosso meio de comunicação com o mundo. Nessa dimensão, podemos falar de um "ser" que se manifesta corporalmente, que se faz significação encarnada no gesto, que enquanto dança torna-se cultura e arte viva.

Para Merleau-Ponty (1999), o corpo humano pode ser considerado o primeiro dos objetos culturais, pois é por meio dele que todos os outros existem. O corpo próprio, enquanto portador de um comportamento, cons- 
trói um ambiente, deixando vestígios no espaço e no tempo que podem tornar-se rastros falantes de uma existência. Entre esses rastros falantes, encontramos toda a cultura de movimento, que pode abrir um diálogo constante na experiência humana a partir de um processo mimético que não escape da aprendizagem, da ressignificação e da (re)criação dos movimentos.

O conceito de imitação ou mimese está historicamente relacionado com o fazer artístico. Ao recorrer à definição trazida pelo dicionário de filosofia Abbagnano, vemos que ele remete o termo imitação para o conceito de estética. Designando-se ciência (filosófica) da arte e do belo, a estética aponta para uma discussão que descreve diferentes entendimentos dessas duas dimensões, visões que se modificam entre a filosofia antiga, moderna e contemporânea.

Resguardadas as diferenças, é pertinente destacar que a definição mais antiga de arte na filosofia ocidental é a de imitação, aquela que pretendia subordinar a arte como imitação da natureza ou da realidade em geral. Nesse sentido, percebemos que a estética acompanha o pensamento de muitos filósofos, e é com Platão, na Antiguidade, que a passividade da imitação artística vai ser destacada. Articulando essa ideia, Platão traz o exemplo da pintura, que, conforme afirma em "A República", "só faz reproduzir a aparência do objeto" (ABBAGNANO, 2007, p.427).

Trazemos essa pequena ilustração do termo para compreender que se pode pensar a imitação em duas direções: uma como pura e simples imitação, ligada à reprodução mecânica, e outra como imitação criativa, que pode estar ligada tanto à representação, quanto à expressão, o que indica um fazer com "expressividade criativa". Essa última mencionada por Merleau-Ponty para tornar possível uma comparação da linguagem com a pintura, enquanto possibilidade significante das operações expressivas.

Como constatado por Merleau-Ponty, é a expressão criadora que torna possível pensarmos as artes como linguagem - a linguagem como arte ações que se tornam eternamente expressivas pela atuação humana, pois não existe uma linguagem petrificada, absoluta, e seu caráter de inacabamento é possível graças à existência humana que faz a expressão surgir novamente, e esse inacabamento é que permite e "reconvoca por inteiro nosso poder de exprimir" (MERLEAU-PONTY, 1974, p.70).

Por isso, Merleau-Ponty (1974, p. 67) diz que "importa compreender a pintura clássica como uma criação, e isto, no próprio momento em que quer ser representação de uma realidade". Ao afirmar isso, o autor salienta que nenhuma pintura consistiu jamais em simplesmente representar.

Portanto, se atentarmos para a expressividade que pode estar presente na imitação artística é possível alargar o seu entendimento e pensar que não só na arte, mas em qualquer ação humana, há uma imitação que se con- 
figura como "expressividade criadora", mesmo quando apenas nomeada como representação. Nesse caso, vemos que a imitação se entrelaça ao que é humano e logo se funde ao social, cultural e ao histórico.

É nesse viés que encontramos em Wulf (2005) uma discussão em relação à educação como mímesis. Descrevendo sobre os processos miméticos na gênese da educação do ser humano, o autor parte de uma problemática antropológica, afirmando que não se trata de apresentar uma teoria mimética da educação, mas sim de levantar uma discussão que esclareça sua importância na formação humana. Wulf apresenta uma discussão do tema filosoficamente e, assim, entrelaça dimensões filosóficas, culturais e históricas, perpassando por conceitos de vários filósofos que discutiram essa temática, como Platão, Aristóteles, Adorno, Benjamin, entre outros.

Para esse antropólogo alemão, "o ato mimético não é mera reprodução, mas ação criativa" (WULF, 2005, p.175). Aproximando-se da ideia de Merleau-Ponty quando aponta a possibilidade de aproximação entre a representação e a criação expressiva, Wulf $(2005$, p. 83) diz que "representar alguma coisa significa também exprimir alguma coisa", uma espécie de representação que já exige criação. E esse é um aspecto de extrema importância, sobretudo no campo das artes e, como exemplo, o autor aponta a música e a dança.

Trata-se de considerar que há possibilidade de uma aprendizagem que respeite a liberdade do outro, na qual "mímesis não significa simples imitação no sentido de produzir cópias. Ela se refere a uma qualidade criativa do homem que lhe permite realizar algo novo" (WULF, 2005, p. 103). É nesse sentido que podemos dizer que o intérprete na dança é um "intérprete criador", visto que a expressividade dos gestos ultrapassa a aprendizagem, surgindo significações e sentidos na experiência viva.

Não há dúvidas que a mímesis marca presença nos processos de aprendizagem da dança. Porém, falta muitas vezes um entendimento da imitação que vá além de um padrão ideal a ser alcançado. Podemos ver, segundo Wulf (2005), que a mímesis torna (ou deveria tornar) possível o acesso não reificado ao outro, um acesso que respeita a liberdade do outro, e, sobretudo, envolve uma aproximação do outro que ocorre sem violência. Como exemplo, podemos observar o desejo do agir mimético já na primeira infância, que se expressa no falar, no comportar-se, na repetição e no aperfeiçoamento dos primeiros gestos sonoros e nas tentativas de movimento (GEBAUER; WULF, 2004).

Podemos acrescentar que essa aprendizagem dos gestos que ocorre em situações da vida cotidiana com o outro liga-se à intencionalidade corpo- 
ral original ${ }^{3}$, que permite ao ser humano ir além do mundo dado, ao encontro de uma significação operante. Dentro de uma perspectiva fenomenológica podemos dizer que há um Ser da expressão, e esse possui o poder de ultrapassar os signos indo ao encontro dos sentidos, pois "os signos organizados possuem seu sentido imanente, que não se prende ao 'penso', mas ao 'posso'”' (MERLEAU-PONTY, 1991, p. 94).

Sabemos, então, que a aprendizagem mimética está presente constantemente na vida humana, seja na aprendizagem de uma dança, seja na aprendizagem de um gesto do cotidiano qualquer, como vemos ser comum na relação entre a criança e o adulto.

Nesse sentido, cabe destacar que não se trata de forma alguma em negar a aprendizagem das diferentes técnicas específicas da dança, mas sim, em refletir sobre como explorar o grande repertório de gestos que ela abarca, sem o limite de um sistema de signos arbitrários. Afinal, observamos, segundo Porpino (2006, p. 98), que a "aprendizagem da cultura é a apropriação do sentido da existência, mas esta apropriação é ao mesmo tempo criação nova e perspectivas de múltiplas recriações dessa mesma cultura".

Assim, nos fica a seguinte questão: ao aprendermos os gestos projetados em uma determinada época/contexto, não poderíamos evocá-los e, ao mesmo tempo, ressignificá-los em nossos próprios movimentos?

Dessa forma, é pertinente enfatizar que a aprendizagem das diferentes técnicas específicas da dança pode vir acompanhada de uma aprendizagem que contemple a intencionalidade da "imagem ou ideia de movimento (KUNZ, 2001) ${ }^{4}$ e não somente a uma cópia mecânica e fragmentadora.

Para tanto, é necessário que se criem estratégias pedagógicas que permitam essa abertura no aprender o movimento durante o processo de ensino, no qual a experimentação ocorre segundo a orientação do movimento trazido pelo professor, mas com espaço para que nesse processo de igualarse ao outro, o próprio sujeito se transforme (GEBAUER; WULF, 2004). Isso

\footnotetext{
3 Segundo Merleau-Ponty (1999) o movimento do corpo só desempenha um papel na percepção do mundo se ele próprio é uma intencionalidade original, uma maneira de se relacionar com as coisas, distinta do conhecimento.

$4 \quad$ Baseando-se nos estudos dos holandeses, Carl C. F. Gordijn e Jan W.I. Tamboer, Kunz (2001, p.175/176) descrevem as três formas de transcendência de limites pelo "semovimentar". A forma direta refere-se à transcendência de limites numa intenção espontânea de movimento, envolvendo uma forma não pensada e direta, um saber corporal que é pré-reflexivo. Na forma aprendida, ocorre uma transcendência de limites pela aprendizagem, nesse caso por meio de uma ideia de movimento ou uma imagem de movimento, há uma intencionalidade que se constrói. A terceira, forma criativa/inventiva, centra-se numa intencionalidade que transcende limites através da criação e invenção dos movimentos. A aprendizagem a que nos referimos agora, especialmente, diz respeito à segunda etapa: a forma aprendida.
}

Pensar a Prática, Goiânia, v. 17, n. 3, p. 849-864, jul./set. 2014 
quer dizer que "[...] ao refazer em meu corpo o sistema de gestos já instituído por outrem [...] crio novas orientações [...]" (MÜLLER, 2001, p. 217). Nesse sentido, o gesto do outro está diante de mim como uma questão, convidando-me a encontrar seu sentido nele próprio (MÜLLER, 2001).

Para Wulf (2005), a relação mimética se define em função de algo dado - nesse caso podemos incluir a imitação da intenção de um movimento (KUNZ, 2001) - mas esse modelo, segundo o autor, é caracterizado pela sua abertura quanto ao seu resultado. Assim, é importante destacar que "os processos miméticos se dão com 'intenções rompidas', eles ocorrem sem que seja, no início, clara a direção que eles tomarão e qual será o seu resultado. É o caráter aberto de tais processos que os distinguem de mera imitação [...]" (WULF, 2005, p. 58).

Nessas condições, Wulf (2005, p.57) enfatiza que "a liberdade, a autonomia e a criatividade individual são condições indispensáveis para os processos miméticos". Conforme o autor, na aprendizagem mimética dos gestos, os seres humanos passam a serem inseridos na cultura; é preciso, no entanto, lembrar que as tradições culturais sofrem atualizações pelo uso dos gestos e são assim adaptadas à atualidade, segundo o contexto histórico e social que as conferem. Com espaço para iniciativa e criação, pouco a pouco vão se alterando as formas de expressão, representação e os significados dos gestos.

Ao experimentar os movimentos dançantes, via processo de imitação de uma intenção (KUNZ, 2001), os sujeitos podem compreender os gestos e, ao mesmo tempo, descobrir neles seu "estilo próprio". De acordo com Merleau-Ponty (1974), o estilo aparece do ponto de contato do pintor e do mundo, sendo que, em sua percepção, já se pode notar a presença de uma certa "percepção estilizada" (p. 73), termo que o filósofo utiliza de Malraux ${ }^{5}$ , para indicar que em toda percepção já há uma maneira particular que o ser possui de habitar, tratar e interpretar o mundo, pois para Malraux o estilo "é um meio de recriar o mundo".

Nesse caso, em uma aula de dança, mesmo frente a intenções de movimento que o professor apresenta, as quais possuem formas definidas, é possível haver um diálogo entre suas propostas de movimento e as experiências subjetivas dos alunos.

Quando estamos aprendendo a escrever, inicialmente apenas copiamos as palavras com certa intenção de acertar, mas logo em seguida transcendemos essa fase e começamos a escrever frases, parágrafos, até que produzimos um texto. E é isso que, normalmente, falta no ensino-aprendizagem da dança, porque, muitas vezes, os alunos permanecem apenas na cópia

$5 \quad$ Obra: La Création esthétique (1948).

Pensar a Prática, Goiânia, v. 17, n. 3, p. 849-864, jul./set. 2014 
mecânica de passos, não há situações que lhes permitam exercer uma imitação aberta e criativa e, assim, tornam-se poucas as situações de reelaboração ou de produção artística ${ }^{6}$.

Percebe-se que o problema não está na utilização das técnicas específicas da dança, mas sim na forma como elas são levadas ou apresentadas aos sujeitos, pois as técnicas são construídas culturalmente, porém quando retiradas dos seus contextos de criação e transpostas para outros contextos, deve haver o cuidado para não transformá-las em simples imposição de movimentos a serem apenas repetidos e copiados.

Nesse sentido, Porpino (2006), com base em Mauss (1974), expõe que a aprendizagem das técnicas corporais não se resume a uma cópia descontextualizada. Ao contrário disso, implica um educar que se sobrepõe e vai além de um simples imitar.

Todavia, são as maneiras de oferecer as propostas que podem mudar todo o sentido da experiência. Como constatado na dança-improvisação (SARAIVA, 2003; 2009), as propostas e as formas de trabalho podem ser abordadas dentro de uma perspectiva que se diferencie das formas tradicionais. Nessas condições, Saraiva exemplifica que, nos conteúdos a serem desenvolvidos, é possível permitir que formas de dançar, como o jazz, o tango, a dança moderna ou o folclore façam parte das aulas, das quais podem se aproveitar seus componentes técnicos originais, mas levando em consideração "que as técnicas corporais são 'encontradas' nos processos de experimentação, a partir de cada corpo-sujeito" (SARAIVA, 2003, p. 372).

\section{Do mundo vivido}

Chegamos, agora, a um ponto fundamental, quando pensamos na dança voltada para a escola. Até então, visualizamos algo que consideramos importante diferenciar nos processos de aprendizagem do movimento humano: uma intenção aberta e uma intenção fechada no aprender o movimento. Enquanto a aberta se relaciona à "aprendizagem artística" que permite a fluência, a busca de um estilo próprio, a fechada está voltada à "aprendizagem mecânica", que visa uma igualdade, uma adaptação do sujeito a um padrão de movimento. Mas, após distinguirmos essas duas dimensões da aprendizagem, ainda fica o questionamento - fazendo referência ao título inicial - de como é possível um diálogo entre o mundo vivido, o "mundo de movimen-

6 Esta situação é apontada por Marques (2003) e Fiamoncini (2003), quando ressaltam a presença dominante na escola de reprodução de coreografias para apresentação em eventos comemorativos que seguem o calendário escolar.

Pensar a Prática, Goiânia, v. 17, n. 3, p. 849-864, jul./set. 2014 
tos" do próprio sujeito e essa imitação criativa nas propostas de dança voltadas ao contexto da educação.

Nesse sentido, vale relembrar a importância do mundo vivido nas criações artísticas, que é base para a existência da arte. Como se pode notar, não é difícil avistar que a fenomenologia pontyana está cheia de conexões entre a arte e mundo percebido. $O$ filósofo enfatiza o mundo como vivência, sendo o mundo aquilo que eu vivo. Da mesma forma, há uma abertura do ser com o mundo, estou aberto ao mundo e ele é inesgotável. $\mathrm{O}$ "retorno às coisas próprias", enfatizado na fenomenologia, sempre está relacionado ao mundo da experiência, o retorno à experiência em seu estado originário.

Isso tudo, como se pode perceber, é o grande momento de encontro da arte com a fenomenologia. Segundo Matthews (2010) com base em Merleau-Ponty (2002), a arte, especialmente a moderna, volta a percepção num sentido mais básico, que pode ser definido como um acesso à verdade. Nesse sentido, Merleau-Ponty (1999, p.19) diz que "a filosofia não é o reflexo de uma verdade prévia, mas assim como a arte, é a realização de uma verdade".

Podemos dizer que no mundo artístico não existe apenas uma verdade, mas sim o infinito, o inesgotável, o por fazer. É, antes, segundo Matthews (2010, p.183), "a maneira como palavras comuns podem ser usadas para criar mundos paralelos que nos levam a ver de forma diferente o mundo em que vivemos".

Assim, esses movimentos comuns, que podemos chamar de movimentos do cotidiano, ou de "mundo de movimento" do próprio sujeito, podem fazer toda a diferença no processo de elaboração artística quando são explorados nas experiências. Fraleigh (1996) destaca que na criação artística o ponto zero está em nós mesmos, na imaginação originária, sendo que na dança, ela nasce do corpo vivido. É nesse sentido que "as respostas dos sujeitos ao mundo em nível pré-reflexivo" (ARAÚJO et al., 2010, p. 07), correspondentes à "forma direta de experimentação do movimento" (KUNZ, 2001, p. 175), podem exercer grande importância nas experiências educativas.

Nessa perspectiva, na vivência direta do "se-movimentar" (KUNZ, 2001), apontamos a pertinência de propor o que podemos nomear de "situações-problema", situações essas lançadas para que os alunos possam resol-

Expressão corrente na fenomenologia de Husserl, filósofo que deu início ao "movimento fenomenológico". A expressão muitas vezes é também chamada de retorno "às coisas mesmas", correspondente à redução fenomenológica, podendo ser entendida como um "[...] deixar o mundo, ou o Ser falar por si" (MATTHEWS, 2010, p. 22). Futuramente o termo é retomado por Merleau-Ponty que investe em reflexões entrelaçadas com a obra de arte.

Pensar a Prática, Goiânia, v. 17, n. 3, p. 849-864, jul./set. 2014 
ver. As "situações-problema" visam instigar os sujeitos a investigar e experimentar variadas formas de "se-movimentar", nas quais não há necessidade de apontar um modelo de movimentação, mas sim de partir das possibilidades do "corpo próprio em situação", ou seja, de oportunizá-lo para a exploração das mais variadas formas de "se-movimentar" em nível pré-reflexivo.

Há uma indicação da tarefa, mas a forma com que ela irá ser resolvida partirá de cada sujeito ${ }^{8}$. É nesse sentido que vemos a importância de alternar os momentos pedagógicos das experiências, incluindo, além da imitação da intenção do movimento, como vimos anteriormente, a forma direta de experimentação a que nos referimos agora, assim como a forma criativa/inventiva sobre a qual falaremos adiante.

A intenção de uma tarefa com "situações-problema" pode ser exemplificada da seguinte forma: sem indicar apenas uma forma pronta de rolar para os alunos, professores podem propor que atravessem a sala, de forma que várias partes do corpo toquem o chão. Ao expor isso, cada aluno em sua individualidade irá descobrir novas formas de rolar e, a partir dessas descobertas, será ampliado o repertório de movimentos do que corresponde a ex-

8

Apontamos como exemplo, a experiência de intervenção pedagógica da primeira autora desse texto, que corresponde a aulas de dança para crianças e adolescentes de sete a 16 anos, em um projeto extracurricular, junto a seis escolas da rede pública de ensino no ano de 2009. "Sempre solicitava em uma atividade que os alunos se deslocassem no espaço da sala "se-movimentando" como quisessem: pulando, saltando, andando, rolando, rastejando, etc. Ao meu sinal, ou ao cessar o som da música, elas deveriam parar em um "movimento-pose" escolhido por elas, sendo que a intenção principal deste momento era explorar a expressividade criativa do "movimento-pose", que poderia ocorrer nos três níveis de movimento (baixo, médio, alto). A atividade consistia sempre em fazer com que as crianças, após a criação de aproximadamente quatro ou cinco "movimento-pose", lembrassem o local da sala em que os realizaram, bem como a forma de cada "movimentopose" criado. Em seguida, procedia-se com ações de troca de lugares, para voltar ao "movimento-pose" um, ao "movimento-pose" dois, e assim sucessivamente. Dessa forma, havia tanto deslocamentos com movimentação diferenciada da forma de andar convencional, quanto a criação de figuras corporais exploradas pelos próprios alunos em nível pré-reflexivo. E, então, algumas vezes aproveitávamos essas trocas de lugares e essas figuras com movimentos para parte de uma futura sequência coreográfica. É importante ressaltar que, durante esse processo de investigação dos movimentos, o inesperado sempre estava presente. No meio do desenvolvimento da atividade, sem indicar como poderia ser realizado o "movimento-pose", as crianças começavam a interagir, criando poses em duplas, trios e, às vezes, até em grupos. Ficava sempre surpresa com a facilidade que elas tinham em entrelaçar os movimentos e fazer surgir figuras criativas, o que contribuía para que a atividade fosse prazerosa, na qual havia uma significação sempre animando os movimentos".

Pensar a Prática, Goiânia, v. 17, n. 3, p. 849-864, jul./set. 2014 
periência de rolar, que podem em outra ocasião até serem transpostos às produções coreográficas.

Claro que esse é um dos mais simples exemplos que podemos dar, pois a dança enquanto movimento e expressividade possui elementos constituintes, como: tempo, espaço, peso, equilíbrio, fluxo, entre outros, que podem ser explorados em uma infinidade de "situações-problema".

Dessa forma, ao privilegiar um planejamento que vise tanto às experimentações/investigações de movimentos em "situações-problema", quanto à aprendizagem de elementos técnicos dos diversos estilos de dança, é possível estabelecer um diálogo que valorize as experiências já trazidas do mundo vivido de cada sujeito e as diversas formas de dançar. Assim, permitimos que nesse processo de ensino-aprendizagem haja espaço para um:

[...] “sujeito criador", a partir de sujeitos cuja expressão interior e emoções humanas já estão mediatizados pela vivência cultural e pelo meio que os cerca; um sujeito histórico, que emerge nos processos educativos imprimindo, também, seu "registro" nas suas "produções" (SARAIVA, 2003, p. 371).

Consideram-se, então, três processos importantes a serem observados no ensino da dança: a exploração do mundo de movimentos dos alunos, com investigação e experimentação de movimentos particulares a partir de uma situação-problema (forma direta); a vivência de elementos das técnicas específicas da dança, sequência/repertórios de movimentos que são trazidos pelo professor ou pelos próprios alunos (forma aprendida/imitação da intenção), pois quanto maiores forem as suas experiências e contatos com essas vivências corporais, maiores podem ser as suas possibilidades para criação; por fim, o lançamento de oportunidades para que os alunos possam reelaborar as suas movimentações aprendidas (forma criativa/inventiva). Nessa ressignificação pode ocorrer um diálogo com movimentações trazidas pelos

9 Ver estudos da coreologia de Laban (1978, 1991). Bailarino, coreógrafo e educador do movimento, Laban desenvolveu estudos teóricos e práticos sobre a arte do movimento. Coreologia é o que ele definiu como uma espécie de gramática e sintaxe da linguagem do movimento. Esse estudo, entre outros aspectos, inclui a Corêutica: estudo do movimento no espaço/formas e a Eukinética: estudo das dinâmicas/qualidades expressivas do movimento. Ver também, proposta da dança-improvisação (SARAIVA-KUNZ, 2003), e contato-improvisação de Steve Paxton (GIL, 2004).

(SARAIVA-KUNZ, 2003), e contato-improvisação de Steve Paxton (GIL, 2004).

Pensar a Prática, Goiânia, v. 17, n. 3, p. 849-864, jul./set. 2014 
alunos e professor, na qual se podem reinventar os movimentos de muitas maneiras.

Aí voltamos à temporalidade que vive no próprio ser humano, pois todos os movimentos já experimentados pelo sujeito no mundo vivido são condições de possibilidade para que ele se abra a novas movimentações criativas. Segundo Merleau-Ponty (1999, p. 194), "a cada instante de um movimento, o instante precedente não é ignorado, mas está como que encaixado no presente, e a percepção presente consiste em suma em reaprender, apoiando-se na posição atual [...]".

No caso da dança, a dança apreendida sempre poderá ser ressignificada no momento atual; ela está à nossa disposição e é condição essencial para que novas danças sejam criadas, pois essa aprendizagem nos lança a um futuro aberto para novas invenções.

Podemos dizer que é neste sentido que Merleau-Ponty (1999, p.212) compara nosso corpo à obra de arte. O corpo, afirma o filósofo, é um nó de significações vivas, "por vezes forma-se um novo nó de significações: nossos movimentos antigos integram-se a uma nova entidade motora [...]". A aprendizagem de um novo gesto, ou

\begin{abstract}
a nova intenção significativa só se conhece a si mesma recobrindo-se de significações já disponíveis, resultando de atos de expressão anteriores. As significações disponíveis entrelaçam-se repentinamente segundo uma lei desconhecida, e de uma vez por todas um novo ser cultural começou a existir (MERLEAU-PONTY, 1999, p.249).
\end{abstract}

Portanto, "ser no mundo" é estar nesse constante diálogo com o mundo da cultura. E no universo da cultura de movimento da dança emprestamos a expressão de Merleau-Ponty (1991) sobre a linguagem para afirmar a existência da possibilidade de uma significação "linguageira" na dança, a qual pode mediar uma intenção ainda muda do sujeito e os seus movimentos.

Assim como Merleau-Ponty (1991), no exemplo da linguagem, nos indica a possibilidade de um surpreender-se com as palavras, podemos sempre nos surpreender com os nossos movimentos na dança, descobrindo-nos infinitamente neles. Então, essa dança dançante que se transforma, e se faz sempre em novas ações, permite que possamos, conforme indica Araújo (2010, p. 86/87), implementarmos " [...] um desenho original com nossa gestualidade que nos permite criar novos sentidos". E aí, como aponta a autora, essa significação "linguageira" das palavras (e acrescentamos dos mo-

Pensar a Prática, Goiânia, v. 17, n. 3, p. 849-864, jul./set. 2014 
vimentos na dança) nos revela nossa singularidade carregada de sentido e afetividade, que são próprias de cada sujeito.

\section{Considerações Finais}

A dança, enquanto cultura de movimento e manifestação artística, configura-se como "cri-ação" humana. Essa ação humana, cultural e social pode e necessita ser recriada e ressignificada em distintas experiências, e é esse foco que destacamos e conferimos numa perspectiva que envolve a experiência do dançar no contexto da educação.

Compreendemos que o processo de aprendizagem dos gestos na dança pode entrelaçar a ação mimética à expressividade criativa. Portanto, trabalhar com as técnicas específicas da dança não significa trabalhar com repetição de movimento em si, podendo haver uma abertura durante o processo de aprendizagem, no qual os alunos possam encontrar seu estilo na experimentação, além de serem possibilitados a reelaborar as movimentações aprendidas. Apontamos, por isso, a necessidade de se construir estratégias pedagógicas para que haja espaço para uma aprendizagem que nomeamos de "aprendizagem-artística", uma aprendizagem que permita a busca de um estilo próprio na experimentação, que permita uma abertura no aprender o movimento.

Além disso, durante esse processo de aprendizagem, conferimos, ainda, ser de extrema importância que as experiências já vividas pelo sujeito - o seu "mundo de movimentos" - dialoguem de forma constante com a aprendizagem das diversas formas de dançar. Isso, tanto por situações lançadas pelo professor para que o aluno possa dar respostas de movimento em nível pré-reflexivo, quanto na criação, na reelaboração, ou na ressignificação de uma sequência de movimentos. Momentos esses que podem ser estruturados de tal forma que haja a possibilidade de se estabelecer um diálogo que valorize as experiências trazidas do mundo vivido de cada sujeito e as diversas formas de dançar.

\section{ABOUT SPECIFIC TECHNIQUES AND THE LIVING WORLD: IMPLICA- TIONS ABOUT THE IMITATION AND CREATION IN DANCE}

\section{Abstract}

This study presents a discussion about the imitation and creation of movements in the context of teaching dance. It is a theoretical essay which is based on MerleauPonty's phenomenology (1991, 1999, 1974), on Kunz's self-move theory (2001) 
and on Wulf's mimesis conception (2005). This study points out the need to build pedagogical strategies so that a "creative imitation" arises, a learning which allows the search for one's own style when performing the movements. Besides, it shows the possibilities of holding a dialogue which gives value to the experiences brought from the living world of each person - his or her world of movements - and the different ways of dancing.

Keywords: Dance. Education. Imitation. Creation.

\section{DE LAS TÉCNICAS ESPECÍFICAS Y DEL MUNDO VIVIDO: IMPLICACIONES SOBRE EL IMITAR Y EL CREAR EN LA DANZA}

\section{Resumen}

El estudio presenta una discusión referente a la imitación y a la creación de movimientos en el contexto de la enseñanza de la danza. Se trata de un ensayo teórico que se fundamenta en la fenomenología de Merleau-Ponty (1991, 1999,1974), en la teoría del "moverse" humano de Kunz (2001) y en la concepción de mimesis de Wulf (2005). El estudio apunta a la necesidad de construir estrategias pedagógicas para que haya espacio para una "imitación creativa", un aprendizaje que permita la búsqueda de un estilo proprio en la ejecución/experimentación de los movimientos. Más allá de eso, indica posibilidades de establecer un diálogo que valorice las experiencias traídas del mundo vivido de cada sujeto - su "mundo de movimientos" - y las diversas formas de danzar.

Palabras-claves: Danza. Educación. Imitación. Creación.

\section{Referências}

ABBAGNANO, N. Dicionário de filosofia. Tradução da $1^{a}$ edição brasileira coordenada e revisada por Alfredo Bosi, Revisão da tradução e tradução dos novos textos de Ivone Castilho Benedetti. 5. ed. São Paulo: Martins Fontes, 2007.

ARAÚJO, L. C. G. Ontologia do movimento humano. 2010. 158 f. Tese (Doutorado em Educação Física) - Centro de Desportos, Universidade Federal de Santa Catarina, Florianópolis, 2010.

ARAÚJO, L. C. G. et al. Ontologia do movimento humano: teoria do "semovimentar" humano. Pensar a Prática, Goiânia, v. 13, n. 3, p. 1-12, set./dez., 2010.

Pensar a Prática, Goiânia, v. 17, n. 3, p. 849-864, jul./set. 2014 
FIAMONCINI, L. Dança na educação: a busca de elementos na arte e na estética. 2003. 106 f. Dissertação (Mestrado em Educação) - Centro de Educação, Universidade Federal de Santa Catarina, Florianópolis, 2003.

FRALEIGH, S. H. Dance and the Lived Body. A descriptive aesthetics. 2. ed. Pennsylvania: University of Pittsburgh Press, 1996.

GEBAUER, G.; WULF, C. Mimese na cultura: agir social - rituais e jogos - produções estéticas. Tradução de Eduardo Triandopolis. São Paulo: Annablume, 2004.

GIL, J. Movimento Total: o corpo e a dança. 2. ed. São Paulo: Iluminuras, 2004.

GONZÁLEZ, F. J; FENSTERSEIFER, P. E. Entre o "não mais" e o "ainda não": pensando saídas do não-lugar da EF escolar I. Cadernos de Formação RBCE. v. 1, n. 1, p. 9-24, set, 2009.

KUNZ, E. Educação Física: ensino \& mudanças. Ijuí: Unijuí, 2001.

LABAN, R. Dança educativa moderna. São Paulo: Ícone, 1991. O domínio do movimento. São Paulo: Summus, 1978.

MARQUES, I. A. Dançando na escola. São Paulo: Cortez, 2003.

MATTHEWS, E. Compreender Merleau-Ponty. Tradução de Marcus Penchel. Rio de Janeiro: Vozes, 2010.

MERLEAU-PONTY, M. Fenomenologia da Percepção. Tradução de Carlos A. R. Moura. 2. ed. São Paulo: Martins Fontes, 1999. Fontes, 1991.

Signos. Tradução de Maria E. G. G. Pereira. São Paulo: Martins O homem e a comunicação: a prosa do mundo. Tradução de Celina Luz. Rio de Janeiro: Edições Bloch, 1974.

MÜLLER, M. J. Merleau-Ponty: acerca da expressão. Porto Alegre: EDIPUCRS, 2001. 
PORPINO, K. O. Dança é educação: interfaces entre corporeidade e estética. Natal: Editora da UFRN, 2006.

SARAIVA, M. C. Elementos para uma concepção do ensino de dança na escola: a perspectiva da educação estética. Revista Brasileira de Ciência do Esporte, Campinas, v. 30, n. 3, p. 157-171, maio, 2009.

SARAIVA-KUNZ, M. C. Dança e gênero na escola: formas de ser e viver mediadas pela educação estética. $451 \mathrm{f}$. Tese (Doutorado em Motricidade Humana). Faculdade de Motricidade Humana, Universidade Técnica de Lisboa, Lisboa, 2003.

WULF, C. Antropologia da educação. Tradução de Sidney Reinaldo da Silva. Campinas: Editora Alínea, 2005.

Recebido em: 17/10/2013

Revisado em: 11/03/2014

Aprovado em: 16/05/2014

Endereço para correspondência:

edf.danieli@gmail.com

Danieli Alves Pereira Marques

Universidade Federal de Santa Catarina, Departamento de Educação Física - Cen-

tro de Desportos.

Campus Universitario CDS Bloco III

Trindade

88400900 - Florianópolis, SC - Brasil 